\author{
배사구 유입부 흐름 및 하상변동 수치모의를 위한 \\ 매개변수 검정 및 민감도 분석에 관한 연구 \\ 장은경 $\cdot$ 임종철 ${ }^{1} \cdot$ 지 운 $^{*} \cdot$ 여운광 \\ 명지대학교 토목환경공학과, ${ }^{1)}$ 서영엔지니어링 \\ (2011년 6월 27일 접수; 2011년 8월 4일 수정; 2011년 9월 2일 채택)
}

\title{
Parameter Calibration and Sensitivity Analysis for Numerical Modeling of Flow and Bed Changes near the Opening Gate for Sediment Release
}

\author{
Eun Kyung Jang, Jong Chul Lim", Un Ji , Woon Kwang Yeo \\ Department of Civil and Environmental Engineering, Myongji University, Yongin 499-728, Korea \\ ${ }^{1)}$ Water Resource Team, Seoyeong Engineering Co., Ltd., Yongin 448-160, Korea \\ (Manuscript received 27 June, 2011; revised 4 August, 2011; accepted 2 September, 2011)
}

\begin{abstract}
The bed change analysis near the opening gate of a dam or weir to release deposited sediments have been conducted mostly using the numerical models. However, the use of unverified input parameters in the numerical model is able to produce the different results with natural and real conditions. Also, the bed changes near the opening gate of a dam or weir calculated with a numerical model could be varied depending on the geometry extent included the downstream area with supercritical flow in the model. In addition, the different time steps could provide different results in the bed change calculation, even though other conditions such as input parameters, geometries, and total simulation time were same. Therefore, in this study, hydraulic experiments were performed to validate the eddy viscosity coefficient which is the one of important input parameters in the RMA2 model and relevant to variation of simulation results. The bed changes were calculated using the SED2D model based on flow results calculated in the RMA2 model with the verified and selected eddy viscosity coefficient and also compared with experimental results. The bed changes near the opening gate were underestimated in the numerical model comparing with experimental results except only the numerical case without the modeling section of sediment release pipe and downstream area where the supercritical flow was produced. For the simulation of minimum time steps, different shapes of scour hole were produced in numerical and physical modeling.
\end{abstract}

Key Words : Bed change simulation, Numerical time step, Sediment release, Sensitivity analysis, Eddy viscosity coefficient

${ }^{*}$ Corresponding author : Un Ji, Department of Civil and Environmental Engineering, Myongji University, Yongin 499-728, Korea

Phone : +82-31-330-6808

E-mail : jiuncivil@gmail.com

\section{1. 서 론}

하천이나 저수지의 상류에서 유입되는 흐름이 하류 지역에 위치한 댐이나 보 등의 수공구조물에 접근하게 되면 하상경사가 작아지고 유속이 감소하게 되어 유사 이송능력 저하로 인한 퇴사현상이 발생한다. 이러한 퇴 사현상이 심해질 경우 댐이나 보 등과 같은 수공구조물 
의 기능적인 측면에 문제를 발생시킬 뿐 아니라 유사퇴 적으로 인한 홍수위상승 등의 문제를 발생시키기도 한 다. 퇴사문제는 저수지, 댐에서 뿐만 아니라 운하에서 선 박 운행을 위해 건설되는 댐, 주운보, 갑문시설 등과 같 은 하천 수공구조물에서도 발생할 수 있다. 주운을 목적 으로 하는수로는 선박이 통과할 수 있는 주운수심이 유 지되어야 하지만 유사의 퇴적으로 주운수심이 유지되 지 못하면 선박항해에 큰 영향을 미치게 된다. 이와같은 퇴사 및 배사 문제해결을 위해 상류와 하류 하천간의 흐 름 차단을 억제하고 상류로부터 유입되는 유사가 댐이 나보상류 부분에 퇴적되는 현상을 방지하기 위해 수문 이 설치되어있는 혹은 상시 개방되어 있는 배사관을 설 치하기도 한다(지 등, 2009).

댐이나 보 등과 같은 수공구조물 주변에서의 하상 변동을 분석하기 위한 연구 방법으로는 크게 수리모 형실험을 활용하는 방법과 수치모의를 활용하는 방법 이 있다. 수리모형실험은 모형과 원형 간의 흐름 상사 성에 대해 Froude 상사법칙을 만족시켜야한다. 유사 이송 및 하상변동을 예측하기 위한 이동상 모형실험 의 경우 저항계수 상사, 무차원 유사입경 상사, 무차원 한계소류력 상사 등의 상사법칙을 고려하여 Froude 상사와 함께 검토해야 한다(Julien, 2002). 하지만 실 제 이동상 수리모형실험에서는 앞서 설명한 4가지 상 사를 모두 만족시키기는 것이 현실적으로 불가능하 다. 반면, 수치모의의 경우 이러한 상사성에 있어서 제 약 없이 손쉽게 여러 흐름 조건이나 하상토 분포 등을 다양하게 적용시킬 수 있는 장점이 있다. 국내에서는 최근에 지 등(2008)이 낙동강 하류를 대상으로 유사 특성과 낙동강하구둑 준설효과에 관한 수치모의를 수 행하였으며, 윤 등(2003)은 한강 하류부의 하상변동 원인을 분석하기 위해 CCHE2D 모형을 활용하였다. 이 등(2006)은 HEC-6 모형을 이용하여 임진강 하상 변동 예측에 관한 연구를 수행하였으며, 안 등(2007) 은 HEC-6 모형을 이용하여 형산강의 장기하상 변동 을 모의하였다. 하지만, 수치모의는 유사거동에 대한 명확한 이론이 성립되지 않아 특정한 경험공식을 이 용해야 한다는 점과 검증되지 않은 매개변수 사용으 로 실제 자연현상과 상이한 결과가 나올 수 있다는 문 제점이 있다(임, 2008).

이러한 수치모의 상의 문제점을 해결하기 위해서
는 실측된 현장자료를 이용해 흐름 계산시 사용되는 와점성계수와 같은 모형의 매개변수 검증 과정이 반 드시 필요하며 하상변동 예측시에는 검증된 모형에서 채택하고 있는 여러 수치모의 조건에 대한 대상하천 의 적용성도 반드시 검토해야 한다. 따라서 본 연구에 서는 일반적으로 댐이나 보에 설치되는 배사관을 단 순화하여 수리모형실험을 수행하였으며 상사의 왜곡 없이 실제모형 크기를 2차원 수치모형의 적용한 후 유 입부 흐름 및 하상변동을 계산하고 상호비교 분석과 정을 통해 매개변수 검증 및 수치모의 조건에 따른 민 감도 분석을 수행하였다.

본 연구의 목적은 첫째, 배사구 유입부에서의 흐름 분석을 위해 RMA2 모형의 입력자료로 사용되는 와 점성계수의 변화에 따른 유속과 수심 결과를 수리모 형실험 결과와 비교 검증하여 민감도 분석을 실시하 고자 한다. 둘째, RMA2 흐름모의 결과를 기초로 $\mathrm{SED} 2 \mathrm{D}$ 모형을 이용하여 배사구 유입부에서의 하상 변동 모의시 사류발생 구간의 포함 여부에 따라 하상 변동 결과가 어떻게 달라지는지를 분석하고자 한다. 셋째, $\mathrm{SED} 2 \mathrm{D}$ 모형을 이용한 하상변동 모의시 계산시 간 간격 설정에 따른 수치모의상의 하상변동 결과 값 의 차이를 분석해 보고 동일한 지형의 서로 다른 경계 조건들을 모의할 경우 동일한 계산시간간격의 적용이 반드시 필요한지에 대해서도 알아보고자 한다.

\section{RMA2와 SED2D 모형의 개요}

\section{1. 흐름분석을 위한 RMA2 모형}

본 연구에서는 2 차원 유한요소모형으로 정류, 부정 류 모의가 가능하고 전,후 처리가 편리한 흐름모의 프 로그램인 RMA2 모형을 이용하였으며 기본방정식은 다음과 같다. RMA2 모형의 기본방정식인 수심평균 된 2차원 천수방정식은 자유 수면을 가진 물의 운동을 기술하는 3차원 Navier-Stokes 방정식의 일반식을 수 심방향으로 적분함으로서 유도될 수 있다. 이때 연직 방향의 가속도항은 무시하여 압력항을 정수압 분포로 처리하며, 유체는 비압축성이라 가정한다. 수심 적분 된 2차원 천수방정식의 연속방정식과 운동량방정식 은 다음과 같다(EMRL, 2000). 


$$
\begin{gathered}
\frac{\partial \mathrm{h}}{\partial \mathrm{t}}+\frac{\partial(\mathrm{uh})}{\partial \mathrm{x}}+\frac{\partial(\mathrm{vh})}{\partial \mathrm{y}}=0 \\
\frac{\partial \mathrm{u}}{\partial \mathrm{t}}+\mathrm{u} \frac{\partial \mathrm{u}}{\partial \mathrm{x}}+\mathrm{v} \frac{\partial \mathrm{u}}{\partial \mathrm{y}}+\mathrm{g}\left(\frac{\partial \mathrm{h}}{\partial \mathrm{x}}+\frac{\partial \mathrm{a}_{0}}{\partial \mathrm{x}}\right) \\
-\frac{\epsilon_{\mathrm{xx}}}{\rho} \frac{\partial^{2} \mathrm{u}}{\partial \mathrm{x}^{2}}-\frac{\epsilon_{\mathrm{xy}}}{\rho} \frac{\partial^{2} \mathrm{u}}{\partial \mathrm{y}^{2}}+\frac{\mathrm{gu}}{\mathrm{C}^{2} \mathrm{~h}} \sqrt{\mathrm{u}^{2}+\mathrm{v}^{2}}=0 \\
\frac{\partial \mathrm{v}}{\partial \mathrm{t}}+\mathrm{u} \frac{\partial \mathrm{v}}{\partial \mathrm{x}}+\mathrm{v} \frac{\partial \mathrm{v}}{\partial \mathrm{y}}+\mathrm{g}\left(\frac{\partial \mathrm{h}}{\partial \mathrm{y}}+\frac{\partial \mathrm{a}_{0}}{\partial \mathrm{y}}\right) \\
-\frac{\epsilon_{\mathrm{yx}}}{\rho} \frac{\partial^{2} \mathrm{v}}{\partial \mathrm{x}^{2}}-\frac{\epsilon_{\mathrm{yy}}}{\rho} \frac{\partial^{2} \mathrm{v}}{\partial \mathrm{y}^{2}}+\frac{\mathrm{gv}}{\mathrm{C}^{2} \mathrm{~h}} \sqrt{\mathrm{u}^{2}+\mathrm{v}^{2}}=0
\end{gathered}
$$

여기서, $\mathrm{u}, \mathrm{v}$ 는 $\mathrm{x}, \mathrm{y}$ 방향의 유속, $\mathrm{h}$ 는 수심, $a_{0}$ 는 하상 표고, $\epsilon_{x x}, \epsilon_{x y}, \epsilon_{y x}, \epsilon_{y y}$ 는 와점성계수이며 C는 Chezy 공 식의 Chezy 계수, $\rho$ 는 유체의 밀도를 나타내고 있다.

\section{2. 하상변동 모의를 위한 SED2D 모형}

본 연구에서 사용한 SED2D 모형은 2차원 정상적 및 동수역학적인 유사이송과 하상변동을 분석하는 프로그 램이다. 유한요소망에서 SED2D의 계산은 Arithurai 등 (1977)이 제안한 이송-확산 방정식을 기초로 하며 다 음과 같다.

$$
\begin{aligned}
& \frac{\partial \mathrm{C}}{\partial \mathrm{t}}+\mathrm{u} \frac{\partial \mathrm{C}}{\partial \mathrm{x}}+\mathrm{v} \frac{\partial \mathrm{C}}{\partial \mathrm{y}} \\
& =\frac{\partial}{\partial x}\left(D_{x} \frac{\partial C}{\partial x}\right)+\frac{\partial}{\partial y}\left(D_{y} \frac{\partial C}{\partial y}\right)+\alpha_{1} C+\alpha_{2}
\end{aligned}
$$

여기서, $\mathrm{C}=$ 농도 $\left(\mathrm{kg} / \mathrm{m}^{3}\right), \mathrm{t}=$ 시간 $(\mathrm{sec}), D_{x}, D_{y}=$ $\mathrm{x}, \mathrm{y}$ 방향 유사확산계수, $\alpha_{1}=$ 하상근원(bed source)에 대한 계수(l/sec), $\alpha_{2}=$ 하상공급(bed source)의 평형농 도부분 $\left(\mathrm{kg} / \mathrm{m}^{3} / \mathrm{sec}\right)$ 이다. 총유사량 $\mathrm{C}_{\mathrm{eq}}$ 를 계산하는 많은 이송관계식이 있으나, SED2D의 경우 Ackers and White(1973)공식만을 사용한다. SED2D에서 채 택하여 사용되는 Ackers and White(1973) 공식은 에 너지 개념 형태의 식으로써 무차원 유사량은 이동 수 (mobility number)에 관계한다는 차원 해석에서 출발 한다. 이 공식은 중소하천에 적용했을 때와 중앙입경 이 $0.04 \mathrm{~mm}$ 보다 크고 $D_{35}$ 가 $4 \mathrm{~mm}$ 보다 작은 경우에
적용하는 것이 결과 값의 신뢰성이 높다. 유사량 공식 들의 민감도분석 결과(한국건설기술연구원, 1989)에 의하면, Ackers and White 공식은 하상토 입경이 0.25 $\mathrm{mm}$ 보다 작은 영역에서 유사량이 과다하게 추정되기 때문에 이 공식은 세사나 극세사에 대해 적용하기 어 렵다는 평가를 받고 있다. 또한 단일입경에만 적용할 수 있으며 Froude 수가 0.8 이하일 경우에만 사용하도 록 추천하고 있다(EMRL, 2000).

\section{3. 수리모형실험 및 수치모의 조건}

\section{1. 수리모형실험장치 및 조건}

본 실험에서는 수조를 포함한 길이 $25 \mathrm{~m}$, 높이 0.8 $\mathrm{m}$, 그리고 폭 $0.8 \mathrm{~m}$ 의 수로가 사용하였다. 개수로 상 류단에는 고수조에 유입된 물을 받아 유량을 조절할 수 있는 사각 위어(Weir)가 설치되어 있으며 수로의 끝에는 수위를 조절할 수 있는 수문이 설치되어있다. 유량 공급 장치는 고수조, 저수조, 순환수로, 펌프(최 대공급유량 $360 \ell / \mathrm{s}$ )로 구성되어있다. 한편 유속은 1 차원 프로펠러유속계를 이용하였으며 수심은 포인트 게이지를 이용하여 측정하였다. 와점성계수 검정을 위한 수리모형실험의 조건은 Table 1 과 같으며 유속 및 수심은 구조물의 영향을 받지 않는 구조물 전면에 서 상류방향으로 $1 \mathrm{~m}$ 떨어진 지점에서 측정하였다.

배사구 주변에서의 흐름 및 하상변동 수리모형실 험을 위해 Fig. 1 과 같은 아크릴 재질의 배사관를 제작 하였다. 배사구 폭은 $0.3 \mathrm{~m}$ 로 설정하였으며 배사구 높 이 또한 $0.3 \mathrm{~m}$ 로 배사구 형태가 정사각형 모양이 되도 록 제작하였다. 또한 아크릴 하단에서 배사관 입구바 닥 높이는 하상재료 포설높이와 같은 $0.2 \mathrm{~m}$ 로 제작하 였다. 제작된 배사관은 개수로 실험 장치의 유입부에 서 $5.4 \mathrm{~m}$ 떨어진 지점에 설치하였으며 배사구로부터 상류방향으로 $2 \mathrm{~m}$, 하류방향으로 $1 \mathrm{~m}$ 지점의 범위까 지 높이 $0.2 \mathrm{~m}$ 로 하상재료를 포설하였다(Fig. 2). 배사 구 바닥 높이에 따른 수리모형실험을 진행하기 위해 $0.03 \mathrm{~m}$ 와 $0.06 \mathrm{~m}$ 높이의 목재를 배사구 하단에 설치 하여 높이를 조절할 수 있도록 하였다. 배사구 주변에 서의 흐름 및 하상변동 분석을 위한 수리모형실험의 조건은 Table 2와 같으며 실험조건 명칭(예: C086, $\mathrm{C} 344)$ 의 $\mathrm{C}$ 는 $\mathrm{CASE}$ 의 약자이고 첫 번째 숫자는 배사 
구 바닥과 하상과의 높이차, 두 번째 숫자는 하도 경 사, 세 번째 숫자는 유량을 의미한다.

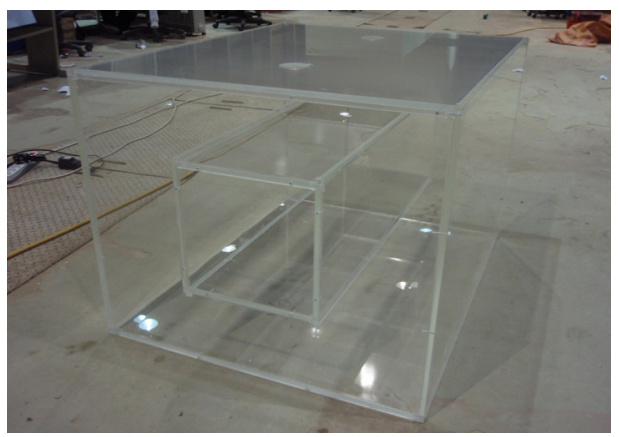

Fig. 1. Sediment release pipe used in experiments.

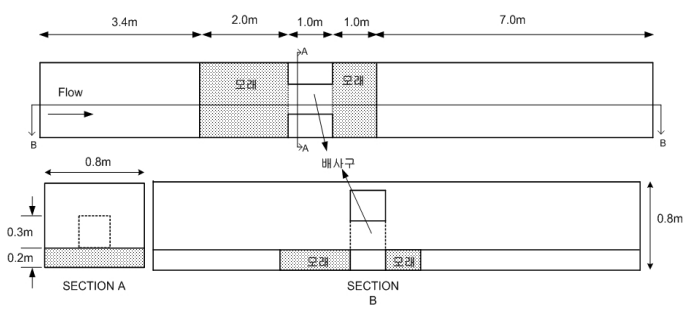

Fig. 2. Layout of experimental open channel.

\section{2. 수치모의를 위한 입력조건}

수치모의시 유한요소해석을 수행하는데 있어서 가 장 중요한 것은 유한 요소망의 구축이다. 와점성계수 분석을 위한 수치모의의 유한요소망은 개수로 실험장 치 및 개수로에 설치된 배사관과 같은 크기로 구성하 였다. 수치모의에서 격자망 크기에 따른 민감도분석 을 위해 3 가지 크기가 다른 격자망 간격으로 지형을 구축하였으며 각각의 격자점수는 4,020 개, 8,042 개, 16,995 개이다. 와점성계수 분석을 위한 수치모의 조 건은 Table 1 과 같으며 유량, 경사 및 하류수위 조건은 수리모형실험과 동일하고 격자점수와 와점성계수를 바꾸면서 민감도 분석을 수행하였다. 와점성계수의 범위는 각 모의조건 별로 지형 및 경계조건에 따라서 수렴 조건 내에 있는 최소 및 최대값으로 설정하였다.

배사구 유입부에서의 하상변동을 위한 수치모의에 서 사용된 유한요소망 또한 수리모형실험에서 사용한 개수로 실험장치 및 아크릴로 제작된 배사구와 같은 크기로 구성하였다. 본 연구에서 사용된 하상변동 모 형인 $\mathrm{SED} 2 \mathrm{D}$ 는 하상조건이 나무 및 콘크리트 재질 등 의 침식활동이 없는 지형을 재현할 수 없고 모두 침식 이 가능한 하상재료로 인식하기 때문에 본 수치모의 에서는 배사구 상류의 지형조건을 수리모형실험에서

Table 1. Experimental cases for eddy viscosity coefficients

\begin{tabular}{|c|c|c|c|c|c|}
\hline Case & $\begin{array}{l}\text { Flow rate } \\
\left(\mathrm{m}^{3} / \mathrm{s}\right)\end{array}$ & $\begin{array}{c}\text { Downstream } \\
\text { depth }(\mathrm{m})\end{array}$ & $\begin{array}{l}\text { Slope } \\
(\%)\end{array}$ & $\begin{array}{l}\text { \# of mesh } \\
\text { points }\end{array}$ & $\begin{array}{l}\text { Eddy viscosity coefficient range } \\
\qquad\left(\mathrm{N}-\mathrm{sec} / \mathrm{m}^{2}\right)\end{array}$ \\
\hline \multirow{3}{*}{ CASE 1} & \multirow{3}{*}{0.06} & \multirow{3}{*}{0.3} & \multirow{3}{*}{1} & (2020 & 10500 \\
\hline & & & & 8042 & $1 \sim 500$ \\
\hline & & & & 16995 & $1 \sim 350$ \\
\hline \multirow{3}{*}{ CASE 2} & \multirow{3}{*}{0.06} & \multirow{3}{*}{0.4} & \multirow{3}{*}{1} & 4020 & $1 \sim 1000$ \\
\hline & & & & 8042 & $1 \sim 1000$ \\
\hline & & & & 16995 & $1 \sim 500$ \\
\hline \multirow{3}{*}{ CASE 3} & \multirow{3}{*}{0.06} & \multirow{3}{*}{0.3} & \multirow{3}{*}{0} & 4020 & $1 \sim 1000$ \\
\hline & & & & 8042 & $1 \sim 1000$ \\
\hline & & & & 16995 & $1 \sim 500$ \\
\hline \multirow{3}{*}{ CASE 4} & \multirow{3}{*}{0.04} & \multirow{3}{*}{0.3} & \multirow{3}{*}{1} & 4020 & $1 \sim 500$ \\
\hline & & & & 8042 & $1 \sim 500$ \\
\hline & & & & 16995 & $1 \sim 350$ \\
\hline \multirow{3}{*}{ CASE 5} & \multirow{3}{*}{0.04} & \multirow{3}{*}{0.4} & \multirow{3}{*}{1} & 4020 & $1 \sim 1000$ \\
\hline & & & & 8042 & $1 \sim 1000$ \\
\hline & & & & 16995 & $1 \sim 500$ \\
\hline \multirow{3}{*}{ CASE 6} & \multirow{3}{*}{0.04} & \multirow{3}{*}{0.3} & \multirow{3}{*}{0} & 4020 & $1 \sim 1000$ \\
\hline & & & & 8042 & $1 \sim 1000$ \\
\hline & & & & 16995 & $1 \sim 500$ \\
\hline
\end{tabular}


Table 2. Experimental cases for the bed change analysis near the opening gate for sediment release

\begin{tabular}{|c|c|c|c|c|c|}
\hline No. & Case & $\begin{array}{l}\text { Entrance bottom height } \\
\text { (m) }\end{array}$ & $\begin{array}{l}\text { Slope } \\
(\%)\end{array}$ & $\begin{array}{l}\text { Flow rate } \\
\left(\mathrm{m}^{3} / \mathrm{s}\right)\end{array}$ & $\begin{array}{l}\text { Downstream depth } \\
\text { (m) }\end{array}$ \\
\hline 1 & C086 & 0.00 & 0.8 & 0.06 & \multirow{12}{*}{0.3} \\
\hline 2 & C084 & 0.00 & 0.8 & 0.04 & \\
\hline 3 & $\mathrm{C} 046$ & 0.00 & 0.4 & 0.06 & \\
\hline 4 & $\mathrm{C} 044$ & 0.00 & 0.4 & 0.04 & \\
\hline 5 & C386 & 0.03 & 0.8 & 0.06 & \\
\hline 6 & C384 & 0.03 & 0.8 & 0.04 & \\
\hline 7 & C346 & 0.03 & 0.4 & 0.06 & \\
\hline 8 & C344 & 0.03 & 0.4 & 0.04 & \\
\hline 9 & C686 & 0.06 & 0.8 & 0.06 & \\
\hline 10 & C684 & 0.06 & 0.8 & 0.04 & \\
\hline 11 & C646 & 0.06 & 0.4 & 0.06 & \\
\hline 12 & C644 & 0.06 & 0.4 & 0.04 & \\
\hline
\end{tabular}

모래포설범위인 배사구 상류 $2 \mathrm{~m}$ 까지 재현하였다. 배 사구 유입부에서의 하상변동 모의를 위한 수치모의 경계조건은 수리모형실험과 동일한(Table 2) 조건으 로 수행하였으며 하상재료 또한 실험에서 사용했던 모래 크기와 동일한 중앙입경 $(0.53 \mathrm{~mm})$ 을 사용하였 다. Crank-Nicholson $\theta$ 값은 Default 값인 0.67을 각각 사용하였으며 유입되는 부유사농도 값은 실제 개수로 모형실험과 같은 조건으로 상류에서 유입되는 부유사 가 없는 것으로 설정하였으며 유사공급은 접근수로에 서만 발생하는 것으로 하였다. 유사확산계수는 100 $\mathrm{m}^{2} / \mathrm{sec}$ 를 사용하였으며 침강속도는 Rubey식에 의해 계산된 $0.0764 \mathrm{~m} / \mathrm{s}$ 를 사용하였다.

\section{4. 와점성계수 분석 및 배사구 유입부에서의 흐름모의 결과}

\section{1. 와점성계수의 선정}

Hardy 등(2000)은 격자망 스케일의 영향을 고려한 와점성계수의 선정이 난류모형의 문제뿐만 아니라 수 치모형의 보정에 더 좋은 결과를 보여준다고 하였다. 본 연구에서는 격자망 간격의 영향을 고려하기 위해 3 종류의 격자망 종류에 따른 와점성계수의 유속과 수 심에 따른 민감도 분석을 실시하였으며 수리모형실험 을 통해 나온 결과와 비교하여 수치모의에서 실제 수 리적 현상과 가장 비슷한 현상을 재현하는 와점성계
수를 선정하였다.

와점성계수 분석을 위한 수리모형실험 결과는 Table 3 과 같으며 배사관 내부에서의 유속은 구조물 상류 $1 \mathrm{~m}$ 지점에서의 유속보다 약 3 배 빠르게 나타났 고 구조물 하류 $0.5 \mathrm{~m}$ 위치에서 유속은 구조물에서 빠 져나온 와류의 영향으로 불규칙하게 나타난 것을 알 수 있다. 실험으로부터 도출해낸 흐름특성 결과는 수 치모의에서 와점성계수를 변화시켜가며 동일한 지점 에서 도출해낸 유속 및 수심과 비교하였고 이는 수치 모형 내 지형자료의 격자점 수에 따라 다르게 나타나 기 때문에 격자점 수 4,020 개, 8,042 개, 16,995 개의 지 형조건에 따라 와점성계수를 다양하게 변화시키면서 동일한 지점에서 수리모형실험의 결과 값(유속과 수 심)과 비교하였다.

CASE 1에 대한 결과를 Fig. 3에 나타내었으며 모 의 결과 CASE 1 에서 격자점 수 4,020개의 지형일 경 우 수리모형실험 결과와 같은 유속 값이 산정된 와점 성계수는 10.693 , 동일한 수심에 대한 와점성계수는 7.389 로 계산되었으며 평균 9.041 인 것으로 분석되었 다. 격자점수 8,042 개일 경우 수리모형실험의 유속 및 수심과 동일한 값이 모의가 되는 와점성계수는 각각 $6.617,7.789$ 이며 평균 8.703이었고, 격자점수 16,995 개에 대해서는 와점성계수는 각각 $9.262,6.316$ 이고 평균 7.789 로 분석되었다. 
Table 3. Hydraulic experimental results for the analysis of eddy viscosity coefficients

\begin{tabular}{ccccccc}
\hline & \multicolumn{2}{c}{1 m upstream } & \multicolumn{2}{c}{ Sediment release pipe } & \multicolumn{2}{c}{0.5 m downstream } \\
\cline { 2 - 7 } Case & $\begin{array}{c}\text { Vel. } \\
(\mathrm{m} / \mathrm{s})\end{array}$ & $\begin{array}{c}\text { Depth } \\
(\mathrm{m})\end{array}$ & $\begin{array}{c}\text { Vel. } \\
(\mathrm{m} / \mathrm{s})\end{array}$ & $\begin{array}{c}\text { Depth } \\
(\mathrm{m})\end{array}$ & $\begin{array}{c}\text { Vel. } \\
(\mathrm{m} / \mathrm{s})\end{array}$ & $\begin{array}{c}\text { Depth } \\
(\mathrm{m})\end{array}$ \\
\hline \hline CASE 1 & 0.258 & 0.270 & 0.882 & 0.240 & 0.196 & 0.248 \\
CASE 2 & 0.198 & 0.349 & 0.600 & 0.331 & 0.128 & 0.342 \\
CASE 3 & 0.211 & 0.318 & 0.720 & 0.290 & 0.145 & 0.293 \\
CASE 4 & 0.202 & 0.252 & 0.677 & 0.344 & 0.090 & 0.245 \\
CASE 5 & 0.146 & 0.347 & 0.459 & 0.290 & 0.141 & 0.351 \\
CASE 6 & 0.157 & 0.318 & 0.720 & 0.297 & 0.124 \\
\hline
\end{tabular}

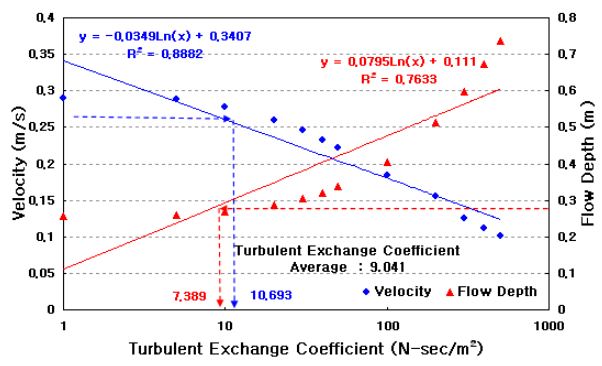

(a) Number of mash points: 4,020

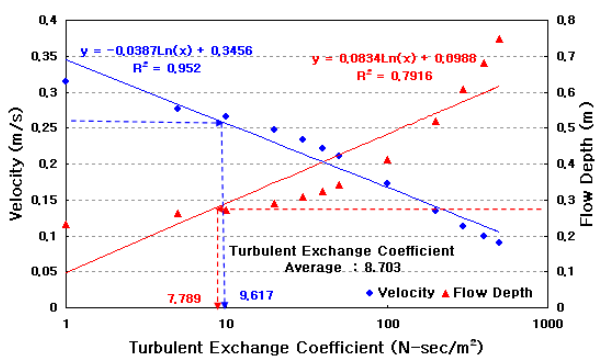

(b) Number of mash points: 8,042

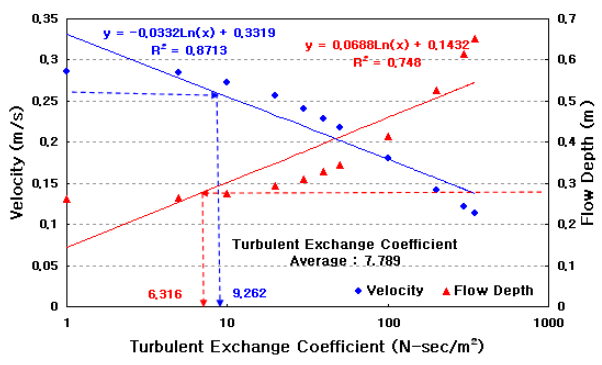

(c) Number of mash points: 16,995

Fig. 3. Numerical modeling results for CASE 1 with various eddy viscosity coefficients.

와점성계수 분석을 위한 수리모형실험과 수치모의 와 결과를 종합하여 Fig. 4와 같은 격자점수와 와점성 계수와의 관계 그래프를 작성하였다. 격자점수가 많 아질수록 유속조건이 빠를수록 수치모의 상에서 실제 현상과 동일한 값을 도출해 내는 와점성계수는 작아 지는 경향이 있으며 유량이 다르면 추세선의 경사가 바뀌는 것을 확인할 수 있다.

도출된 결과(Fig. 3과 4)를 기초로 수행되는 배사구 유입부에서의 흐름 및 하상변동 모의를 위한 최적의 와점성계수를 결정하였다. 배사구 유입부에서의 흐름
및 하상변동 분석을 위한 수치모의에서의 격자점 수 인 8867 개와 경사 $0.8 \%$ 와 $0.4 \%$ 에 맞는 와점성계수를 결정하기 위해서 유량 $0.06 \mathrm{~m}^{3} / \mathrm{s}$ 일 때는 Fig. 4에서 $\mathrm{CASE} 1$ 과 CASE 3 의 추세선을 선형보간 하여 경사 $0.8 \%$ 와 경사 $0.4 \%$ 일 때의 와점성계수를 결정하였으 며, 유량 $0.04 \mathrm{~m}^{3} / \mathrm{s}$ 일 때는 Fig. 7에서 CASE 4와 CASE 6의 추세선을 선형보간 하여 와점성계수를 결 정하였다. 따라서 4.2절의 배사구 유입부에서의 흐름 및 하상변동 모의를 위해 결정된 와점성계수는 Table 5 와 같다. 


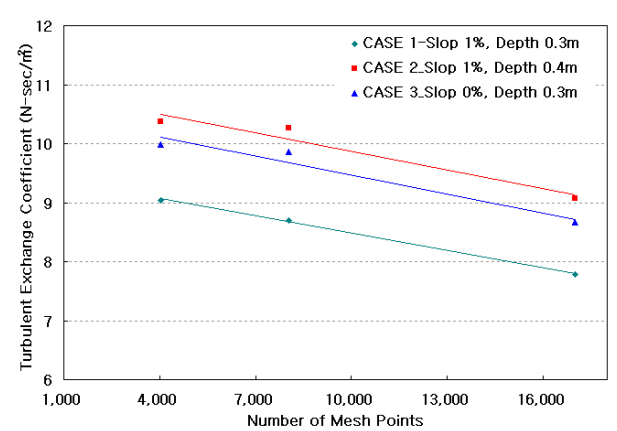

(a) $\mathrm{Q}=0.06 \mathrm{~m}^{3} / \mathrm{s}$

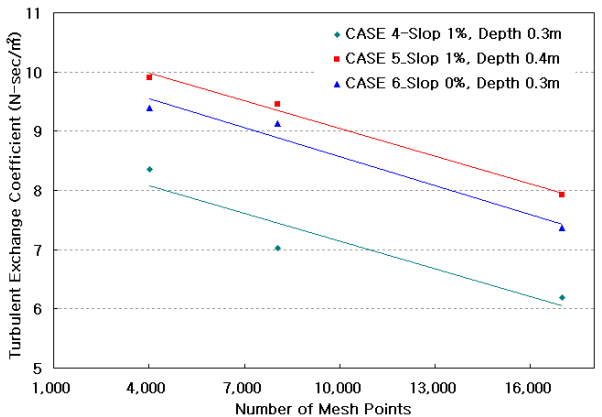

(b) $\mathrm{Q}=0.04 \mathrm{~m}^{3} / \mathrm{s}$

Fig. 4. Number of mash points and eddy viscosity coefficients.

Table 4. Eddy viscosity coefficients calculated for experimental cases of the bed change analysis near the opening gate for sediment release

\begin{tabular}{ccc}
\hline $\begin{array}{c}\text { Flow Rate } \\
\left(\mathrm{m}^{3} / \mathrm{s}\right)\end{array}$ & $\begin{array}{c}\text { Slope } \\
(\%)\end{array}$ & $\begin{array}{c}\text { Eddy viscosity coefficient } \\
\left(\mathrm{N}-\mathrm{sec} / \mathrm{m}^{2}\right)\end{array}$ \\
\hline \hline \multirow{2}{*}{0.06} & 0.4 & 9.22 \\
& 0.8 & 8.79 \\
0.04 & 0.4 & 7.83 \\
& 0.8 & 7.22 \\
\hline
\end{tabular}

\section{2. 배사구 유입부에서의 흐름모의}

본 연구에서는 Table 4 와 같이 선정된 최적의 와점 성계수를 이용하여 배사구 유입부에서의 흐름 특성을 계산한 후 SED2D 모형을 이용하여 배사구 유입부에 서의 하상변동 수치모의를 수행하였으며 그 결과를 수리모형실험 결과와 비교하였다(Fig. 5). 접근유속은 수치모의 결과가 수리모형실험에 비해 약 $0.01 \mathrm{~m} / \mathrm{s}$ 큰 근사한 값을 유지하다가 배사구에 가까워질수록 수치 모의와 수리모형실험의 유속 차는 점점 커지고 배사 구 유입부 부근에서는 수치모의 유속이 수리모형실험 에 비해 약 $0.15 \mathrm{~m} / \mathrm{s}$ 크게 계산된 것을 확인할 수 있다. 수심은 접근수로에서 수리모형실험이 수치모의 보다 약 $0.002 \mathrm{~m}$ 크게 유지되다가 배사구 유입부에서 0.04 $\mathrm{m}$ 떨어진 지점에서 상승하고 다시 배사구 유입부에 다가갈수록 줄어들었으며 배사구 전면에서는 수치모 의가 수리모형실험보다 $0.04 \mathrm{~m}$ 정도 작게 계산된 것 을 확인할 수 있다. 하지만 수리모형실험에서 수심의
변화는 미세하게 감소 하지만 수치모의에서는 변화 폭이 수리모형실험 결과보다 큰 것으로 관측되었다.

\section{5. 배사구 유입부에서의 하상변동 분석}

\section{1. 모의구간에 따른 하상변동 분석}

배사구 유입부에서의 하상변동을 분석을 위해 본 연구에서는 하상변동 모형인 SED2D를 이용하였다. SED2D 모형은 Ackers \& White(1973) 공식을 총유 사량 산정공식으로 채택하고 있으며 이 공식은 Froude 수가 0.8 이하일 경우만 적용할 것을 권고하고 있다 (한국건설기술연구원, 1989). 본 연구에서는 Fig. 6에 서 보는 것과 같이 배사관 내에서 그리고 배사관을 빠 져나온 흐름은 Froude 수가 1이 넘는 사류이며 Ackers \& White공식(1973)을 적용할 수 있는 Froude 수 영역을 벗어나게 된다. 따라서 Fig. 7 과 같이 모의 구간을 4 가지 유형으로 나누어 사류가 발생하는 하류 모의 구간이 배사구 유입부의 하상변동 모의결과에 미치는 영향을 분석하였다. 유형 I은 배사구 상류와 배사관, 배사구 하류구간을 모두 포함한 것이며 유형 는 배사관 길이의 $50 \%(50 \mathrm{~cm})$ 만을 고려한 것이다. 유형 Iㅣ은 배사관 전체길이의 $5 \%(5 \mathrm{~cm})$ 만을 구축하 였으며 유형 $\mathrm{IV}$ 는 배사구 상류에서 배사구 전면까지 만 고려한 조건이다. 수치모의에서의 유형별 하류단 경계조건은 실제로 수리모형실험에서 각 하류단에 해 당되는 지점에서 발생한 수위조건을 경계조건으로 활 용하였다. 


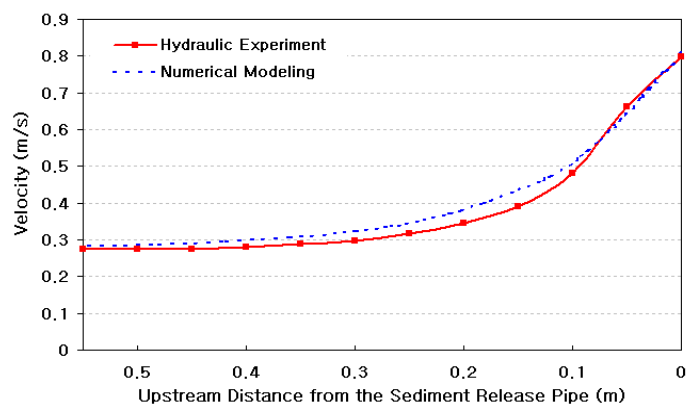

(a) Velocity profile for $\mathrm{C} 086$

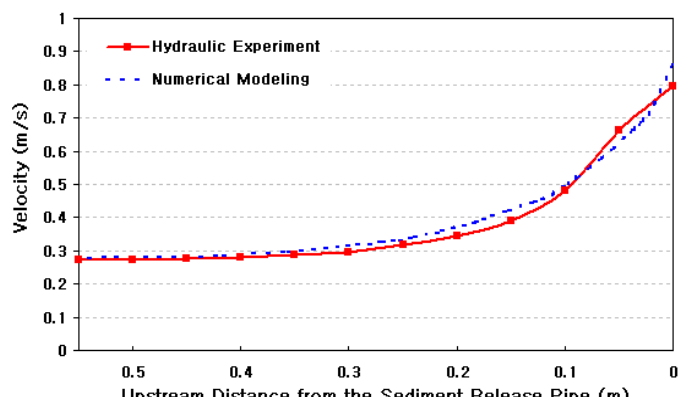

(b) Velocity profile for $\mathrm{C} 386$

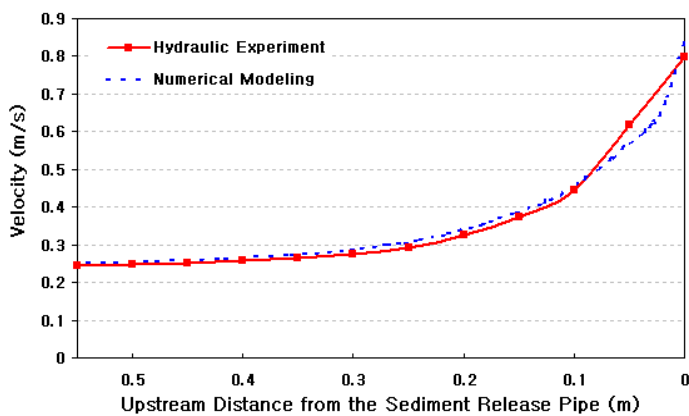

(c) Velocity profile for $\mathrm{C686}$

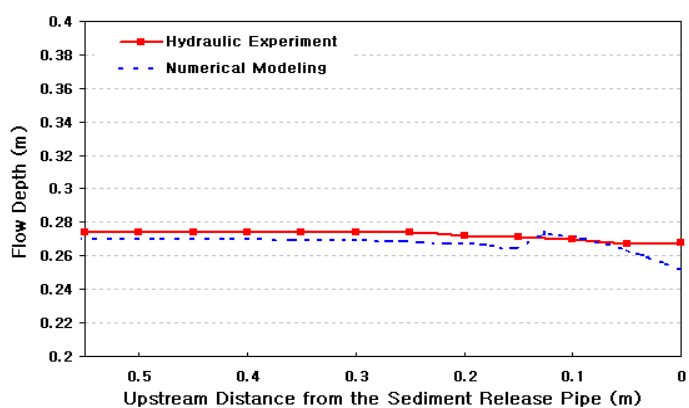

(d) Water depth profile for $\mathrm{C} 086$

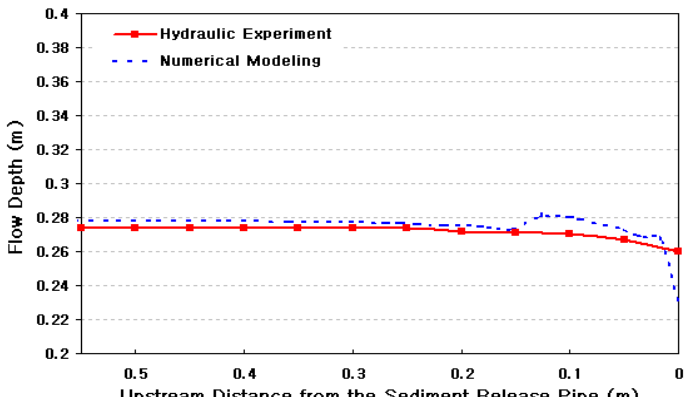

(e) Water depth profile for C386

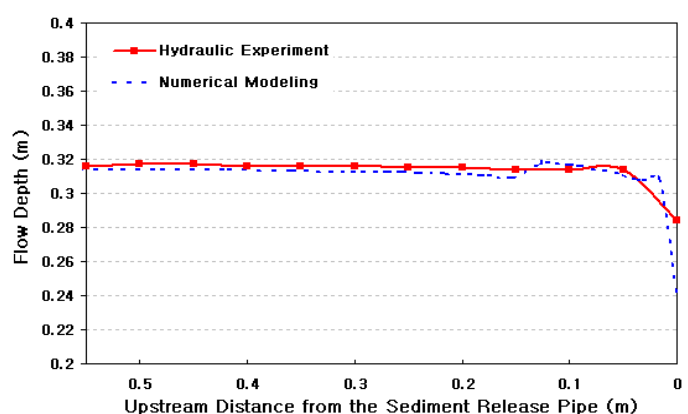

(f) Water depth profile for C686

Fig. 5. Numerical and experimental results of velocity and water depth profiles. 


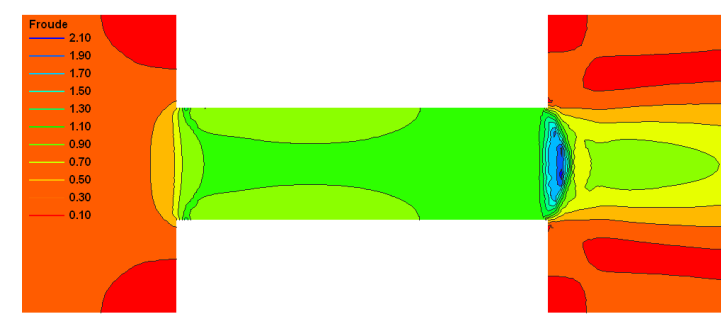

Fig. 6. Froude number distribution of C686(Flow direction $\rightarrow$ ).

수치모의 흐름 결과 4가지 유형 모두 배사구 유입 부에서 상류 $0.2 \mathrm{~m}$ 떨어진 지점까지는 수치모의와 수 리모형실험 값이 서로 근접한 값을 갖지만 배사구 유 입부에서 상류 $0.2 \mathrm{~m}$ 떨어진 지점에서부터는 조금씩 편차가 커지면서 배사구 전면에서는 유속 및 수심차 가 많이 나는 것을 확인할 수 있었다. 특히 유형 IV의 배사구 전면 유속이 다른 유형에 비해 약 $0.17 \mathrm{~m} / \mathrm{s}$ 크 게 계산되었다.

모의구간별 수치모의와 수리모형실험의 하상변동 결과 중 최대 세굴심을 비교하면 Fig. 8과 같다. 수치 모의 결과 배사관의 재현 길이가 길수록 최대 세굴심 은 작게 계산되었으며 유형 $\mathrm{IV}$ 를 제외한 나머지 유형 은 세굴심이 수리모형실험 현상과 비교했을 경우 매 우 작게 계산되는 경향을 보였고 유형 $\mathrm{IV}$ 의 하상변동
예측이 수리모형실험과 가장 근접한 것으로 나타났 다. 또한 배사관의 바닥 높이가 높을수록 수치모의의 최대 세굴심이 수리모형실험 결과에 비해 더 작게 발 생하며 수리모형실험과의 차이는 $\mathrm{C} 086$ 의 경우 각각 17 배, 3.8 배, 3.6 배, 1.88 배, C386일 때는 각각 11.4 배, 4.2배, 3.1배, 1.64배, C686일 때는 각각 122배, 36.1 배, 14.8 배, 2 배의 차이가 있는 것으로 나타났다. 배사 관의 재현길이가 길어질수록 배사관 내의 유속이 빨 라져 배사관 내의 Froude 수가 커지는 현상이 발생하 게 된다. Froude 수가 커짐에 따라 SED2D 모형에서 는 계산수렴의 안정성을 위해 계산간격이 크게 설정 되어야 하며 이로 인해 세굴심은 더 작게 계산되는 결 과가 발생한다. 이러한 이유로 유형 IV에서 가장 큰 세 굴심이 나올 수 있었으며 또한 RMA2 모형을 이용한 흐름모의에서 유형 IV에서 유속이 가장 크게 계산되 었기 때문에 상대적으로 유형 IV의 세굴심이 크게 산 정된 것으로 판단된다. 따라서 향후 $\mathrm{SED} 2 \mathrm{D}$ 를 이용하 여 배사구 유입부에서의 하상변동을 모의시 Froude 수가 큰 구간 즉, 사류 발생 구간은 모의 구간에서 제 외시켜야 실제 최대 세굴심과 가장 비슷한 결과를 도 출해 낼 수 있을 것이다.

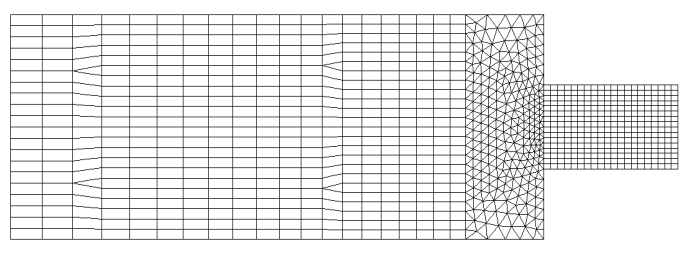

(b) Type II

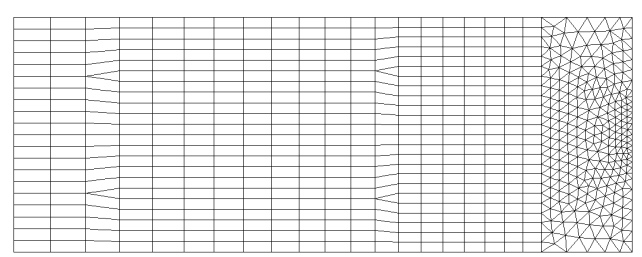

(d) Type IV

(c) Type III

Fig. 7. Four types of modeling section (flow direction $\rightarrow$ ). 


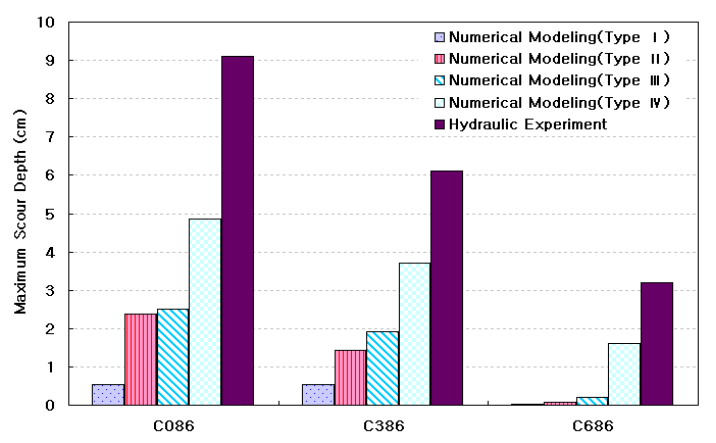

Fig. 8. Numerical and experimental results of the maximum scour depth near the opening gate for sediment release.

\section{2. 수치계산 시간간격에 따른 하상변동 분석}

하상변동 수치모의시 계산 시간간격에 따라 하상 변동 결과는 상당히 큰 차이를 나타내기 때문에 계산 시간간격에 대한 설정은 매우 중요하다. 계산 시간간 격의 설정에 대한 매뉴얼이나 기준은 없으며 모델 사 용자의 주관적인 경험을 바탕으로 선정하는 문제점이 있기 때문에 하상변동 모의 결과에 대한 신뢰성은 떨 어지게 마련이다. 특히 다양한 수리조건에 대한 하상 변동 양상을 서로 비교할 경우 각기 다른 계산 시간간 격을 사용한다며 결과 값 분석에 문제가 있을 것이다. 본 연구에서는 각 모의조건에서 서로 다른 계산 시간
간격을 설정했을 경우와 모두 같은 계산 시간간격을 설정했을 경우에 대해 수치모의와 수리모형실험 결과 를 서로 비교하였다.

각 계산 시간간격의 산출은 모의 조건에서 해가 수 렴하는 최소 계산 시간간격으로 선정하였으며 이 계 산간격보다 작은 값을 적용하여 모의했을 경우 해가 수렴하지 않는 결과가 나타났다. 또한 모든 모의 조건 들이 동일한 계산간격을 갖도록 하기 위해 앞서 선정 한 최소 계산 시간간격 중 가장 큰 계산간격 $(24.5 \mathrm{sec})$ 을 선택하여 모두 동일하게 설정하였다(Table 5).

계산 시간간격이 최소일 때와 동일할 때 하상변동 모의 결과를 수리모형실험 결과와 비교하여 Fig. 9와 같이 나타내었다. Fig. 9에서 C086과 C046, C386과 $\mathrm{C} 346, \mathrm{C} 686$ 과 $\mathrm{C} 646$ 을 살펴보면 계산 시간간격이 최 소일 경우 다른 조건들은 모두 동일함에도 불구하고 경사가 더 작은 조건에서 더 큰 세굴심이 발생한 것을 볼 수 있다. 즉, 수치모의에서 계산 시간간격이 작을수 록 계산 횟수가 더 많아지게 되어 다른 입력 조건이 동 일하더라도 경사가 더 작은 조건에서 세굴심이 크게 산정되는 결과가 발생하였다. 반면, 계산간격이 모두 동일한 경우 실제 수리현상과 동일하게 경사가 급할 수록 유량이 클수록 세굴심이 더 크게 산정되는 것을 확인할 수 있었다. 또한 바닥으로부터 배사관 위치의 높이가 높을수록 세굴심이 더 작게 계산되었으며 수

Table 5. Numerical modeling conditions for various time steps

\begin{tabular}{|c|c|c|c|c|c|c|}
\hline \multirow{2}{*}{ No. } & \multirow{2}{*}{ Case } & \multicolumn{2}{|c|}{ Minimum time step } & \multicolumn{2}{|c|}{ Constant time step } & \multirow{2}{*}{$\begin{array}{l}\text { Simulation } \\
\text { time (hr) }\end{array}$} \\
\hline & & $\begin{array}{c}\text { Time step } \\
\text { length }(\mathrm{sec})\end{array}$ & Number of cycle & $\begin{array}{c}\text { Time step } \\
\text { length }(\mathrm{sec})\end{array}$ & Number of cycle & \\
\hline 1 & C086 & 18.0 & 600 & 24.5 & 450 & \multirow{12}{*}{3} \\
\hline 2 & $\mathrm{C} 084$ & 7.2 & 1500 & 24.5 & 450 & \\
\hline 3 & $\mathrm{C} 046$ & 13.3 & 800 & 24.5 & 450 & \\
\hline 4 & $\mathrm{C} 044$ & 7.2 & 1500 & 24.5 & 450 & \\
\hline 5 & C386 & 24.5 & 450 & 24.5 & 450 & \\
\hline 6 & C384 & 7.2 & 1500 & 24.5 & 450 & \\
\hline 7 & $\mathrm{C} 346$ & 18.0 & 600 & 24.5 & 450 & \\
\hline 8 & $\mathrm{C} 344$ & 10.8 & 1000 & 24.5 & 450 & \\
\hline 9 & C686 & 12.6 & 850 & 24.5 & 450 & \\
\hline 10 & C684 & 7.2 & 1500 & 24.5 & 450 & \\
\hline 11 & C646 & 18.0 & 600 & 24.5 & 450 & \\
\hline 12 & C644 & 10.8 & 1000 & 24.5 & 450 & \\
\hline
\end{tabular}




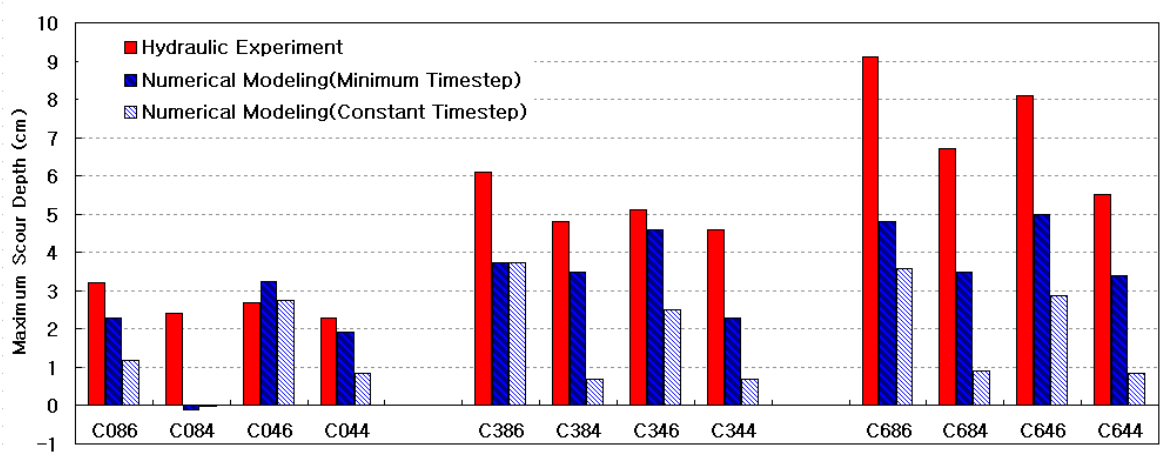

Fig. 9. Maximum scour depths in the experiments and the numerical simulation with different time steps.
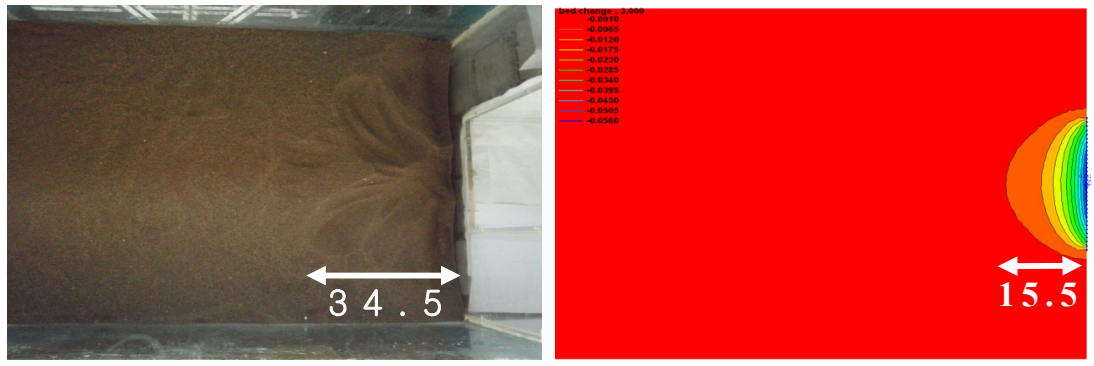

(a) C086, flow direction $\rightarrow$
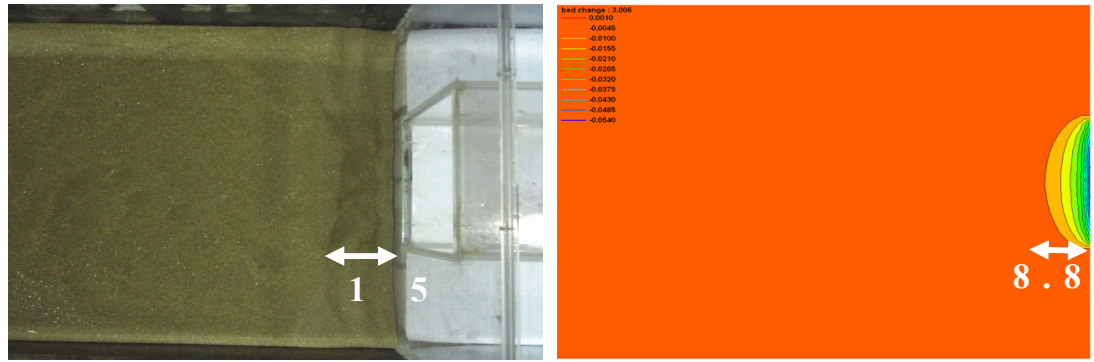

(b) C386, flow direction $\rightarrow$
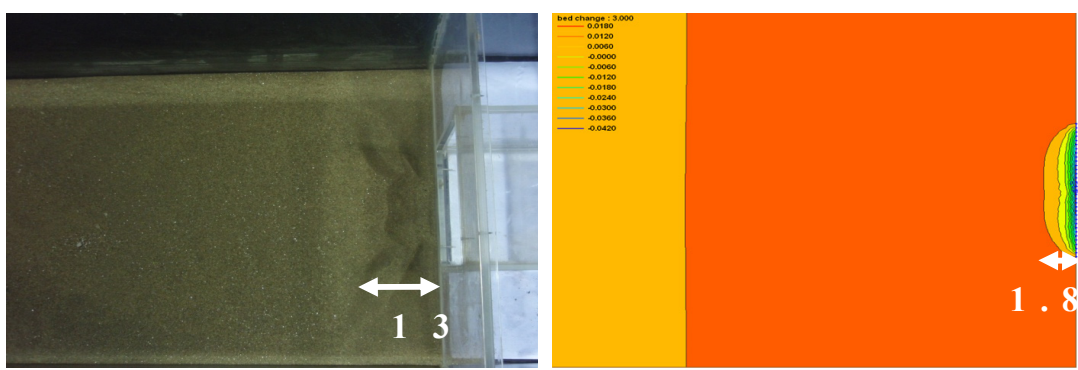

(c) C686, flow direction $\rightarrow$

Fig. 10. Experimental and numerical results of scour hole range with fixed time steps $(24.5 \mathrm{sec})$. 
리모형실험에서도 비슷한 결과를 나타냈다. 경사의 변화보다는 유량의 변화가 클수록 세굴심에 대한 영 향이 더 큰 것으로 나타났다.

또한 수치모의시 계산 시간간격을 모든 조건에서 동일하게 했을 때의 수치모의 결과와 수리모형실험 결과를 평면적으로 비교해 보았으며 그 결과를 Fig. 10 에 나타내었다. 수리모형실험 및 수치모의 결과, 세 굴범위는 C086일 경우 각각 $34.5 \mathrm{~cm}, 15.5 \mathrm{~cm}, \mathrm{C} 386$ 일 경우 각각 $15 \mathrm{~cm}, 8.8 \mathrm{~cm}, \mathrm{C} 686$ 일 경우 각각 13 $\mathrm{cm}, 1.8 \mathrm{~cm}$ 의 결과가 나타났다. 배사구 높이 $3 \mathrm{~cm}, 6$ $\mathrm{cm}, 9 \mathrm{~cm}$ 일 경우 배사구 유입부에서의 세굴범위 차이 는 수리모형실험이 수치모의에 비해 각각 2.2 배, 1.7 배, 7.2 배 크게 발생한 것을 확인할 수 있다. 배사관 위 치의 높이가 높을수록 세굴범위는 더 작아진 것을 볼 수 있으며 수치모의의 세굴형태는 일정한 원 형태로 나온 반면에 수리모형실험의 세굴형태는 대칭적이기 는 하지만 수치모의와는 다른 형태를 갖는 것을 확인 할 수 있다.

\section{6. 결과 및 고찰}

본 연구에서는 RMA2 모형을 이용한 흐름 모의시 와점성계수 값의 변화에 따른 유속과 수심의 민감도 분석을 실시하고 이를 수리모형실험 결과와 비교함으 로써 배사구 주변의 흐름 모의 및 하상변동 모의를 위 한 검증된 와점성계수를 선정하였다. 또한 검증된 와 점성계수를 적용하여 수행된 배사구 유입부에서의 흐 름모의 결과를 기초로, 2 차원 하상변동 모형인 SED2D 를 활용하여 모의구간의 변화와 계산간격 설정에 따 른 하상변동 모의를 실시하였으며 이를 수리모형실험 결과와 비교 분석하였다.

RMA2 모형을 이용한 수치 모의시 와점성계수 값 의 변화에 따른 유속 및 수심의 민감도 분석을 수행한 결과, 배사구에서 상류 방향으로 $50 \mathrm{~cm}$ 떨어진 곳의 유속은 수치모의가 수리모형실험보다 약 $0.01 \mathrm{~m} / \mathrm{s}$ 크 게 계산되었고 수심은 $0.002 \mathrm{~m}$ 작게 계산되었으며 전 반적으로 수리모형실험과 수치모의 결과가 매우 비슷 한 것으로 나타났다. 그러나 배사구 전면에서는 수치 모의가 수리모형실험보다 유속이 $0.15 \mathrm{~m} / \mathrm{s}$ 크게 나왔 으며 수심은 $0.04 \mathrm{~m}$ 작게 계산되어 배사구 유입부에
가까워질수록 수리모형실험과 수치모의 흐름 차이가 커지는 것을 확인할 수 있었다. 또한 본 연구의 수리모 형실험수로를 모의하는데 적용하기 위한 최적의 와점 성계수는 실험 검정 결과를 이용하여 Table 5 와 같이 선정되었다.

사류가 발생하는 배사구 하류 모의구간이 포함되 는 정도에 따라 배사구 유입부에서의 하상변동 결과 에 어떠한 영향을 미치는지를 분석하기 위해 모의구 간을 4가지 유형으로 나누어서 수치모의를 수행하였 다. 4 가지 유형에 대한 분석 결과, 배사관 재현길이가 길어질수록 배사관 내의 Froude 수가 증가하게 되고 이에 따라 SED2D 모형에서 계산수렴을 위한 계산 시 간간격이 크게 설정되어야하는 결과를 초래하게 되며 이는 세굴심이 작게 계산되는 결과를 야기시켰다. 이 로 인해 배사관을 재현하지 않고 유입부만이 수치모 의에 고려된 유형 $\mathrm{IV}$ 에서는 실제 수리모형실험에서의 세굴심과 가장 유사한 세굴심이 계산되었고 이는 다른 유형들 중 가장 큰 세굴심에 해당되는 값이다. SED2D 모형에서 채택하고 있는 유사이송공식인 Ackers와 White(1973) 공식의 적용한계(Froude 수가 0.8보다 작은 경우) 때문에 배사구 하류부(배사관 또는 배사관 하류 영역)를 수치모의에 포함했을 경우 배사구 유입 부에서의 하상변동 결과 값에 많은 차이가 나타났다.

수치계산 시간간격에 따른 배사구 유입부에서의 하상변동 변화를 분석하기 위해 각 조건별 계산간격 을 최소로 하여 수치모의를 수행하였다. 모의 결과, 다 른 조건이 동일하다 할지라도 계산 시간간격이 다를 경우 경사가 작은 조건에서의 최대 세굴심이 경사가 큰 조건보다 최대 $0.96 \mathrm{~cm}$ 더 크게 계산되는 결과가 나타났다. 동일한 계산 시간간격을 갖는 수치모의 결 과와 수리모형실험에서의 세굴 범위를 비교한 결과, 배사관 위치 높이가 높을수록 세굴범위가 더 작아지 는 것을 확인할 수 있었으나 세굴 형태는 수리모형실 험과 수치모의에서 상이한 형태로 발생한 것을 확인 할 수 있었다.

\section{7. 결 론}

본 연구의 결론을 수치모의시 와점성계수 값의 변 화, 적용모의 구간의 변화, 그리고 계산간격 설정 변화 
에 따른 관점에서 간략히 서술하면 다음과 같다.

첫째, 본 연구에서는 2차원 수치모형을 이용한 흐 름 모의시 와점성계수에 따라 다르게 계산되는 유속 및 수심 값의 민감도 분석을 수행하였으며 실제 수리 모형실험 결과 값과의 검증을 통해 최적의 와점성계 수 선정방법을 제시하였다. 본 연구에서 도출된 결과 는 향후 실제하천에서의 수치모의 연구를 수행하는 데 있어 측정된 수위값의 비교를 통해 와점성계수를 선정하는데 기준이 될 수 있을 것으로 기대된다.

둘째, 배사구 주변의 모의 구간 설정에 따른 결과를 통해 배사관 재현길이가 길어질수록 배사관내에서의 유속이 상대적으로 빨라져 Froude 수가 커지는 결과 가 도출됨으로 하상변동모의 결과 값이 실제현상과 많은 차이가 나타나는 것을 확인할 수 있었다. 따라서, 배수구 유입부 주변 하상에 대한 수치모의 수행시 배 사관 또는 배사관 하류의 구간은 제외하고 배사구 유 입부만을 2 차원 모의 영역에 포함시켜야 할 것이다.

셋째, 계산간격 설정은 수치모의 상의 계산간격을 모두 동일하게 하는 것이 신뢰성 있는 수치모의 결과 를 보여줄 것으로 판단된다. 하지만 동일한 지형에 대 해 상호 비교하는 여러 조건의 모의가 아닐 경우는 계 산시간을 한 값으로 설정할 필요는 없으며 다른 수치 매개변수들을 보정하여 계산을 수행해야 할 것이다.

\section{참고 문 헌}

안정민, 류시완, 이남주, 여홍구, 2007, 수치모형을 이용 한 형산강의 장기하상 변동 모의, 2007년도 학술발 표회 논문집, 한국수자원학회, 1272-1276.
윤광석, 김치영, 2003 , 수치모의에 의한 한강 하류부 하 상변동원인 분석, 2003년도 학술발표회 논문집, 대 한토목학회, 1948-1953.

이남주, 황승용, 이삼희, 2006, HEC-6 모형을 이용한 임 진강 하상변동 예측에 관한 연구, 2006년도 학술발 표회 논문집, 한국수자원학회, 1566-1570.

임종철, 2008, 댐이나 보에 설치된 배사구 유입부에서의 흐름 및 하상변동 특성에 관한 수치모의 연구, 석사 학위논문, 명지대학교.

지운, 손광익, 김문모, 2009 , 홍수조절댐에서의 배사관 설치에 따른 상류 하천의 하상변동에 관한 수치모의 연구, 한국수자원학회 논문집, 42(4), 319-329.

지운, Julien, P. Y., 박상길, 김병달, 2008, 낙동강 하류의 유사특성과 낙동강하구둑 준설효과에 관한 수치모의 연구, 대한토목학회 논문집, 28(4B), 405-411.

한국건설기술연구원, 1989 , 하천 유사량 산정방법의 선 정기준개발, 기본연구과제보고서, 한국건설기술연 구원 89-WR-112.

Ackers, P., White, W. R., 1973, Sediment Transport : New arpproach and Analysis. Jorurnal of hydraulic Engineering, 99(HY11), 2041-60.

Ariathurai, R., MacArthur, R. C., krone, R. B., 1977, Mathematical Model of Estuarial Sediment Transport, Technical Report D-77-12, US Army Engineer Waterways Experiment Station, Vicksburg, Miss.

Environmental Modeling Research Laboratory, 2000, SMS RMA-2 WES version 4.5 User's Mannual, Brigham Young University.

Hardy, R. J., Bates, P. D., Anderson, M. G., 2000, Development of a reach scale two dimensional finite element model for floodplain sediment deposition. Pro. Inst, Civ, Eng., Water. Maritime Energ., 132, 141-156.

Julien, P. Y., 2002, River Mechanics. Cambridge University Press, Cambridge, UK. 